\title{
Two-chambers soft actuator bending and rotational properties for underwater application
}

\author{
Muhammad Rusydi Muhammad Razif ${ }^{1}$, Ahmad Athif Faudzi², Ili Najaa Aimi Mohd Nordin ${ }^{3}$, \\ Tariq Rehman ${ }^{4}$, Dyah Ekashanti Octorina Dewi ${ }^{5}$ \\ ${ }^{1,3}$ Faculty of Engineering Technology, Universiti Tun Hussein Onn Malaysia, Malaysia \\ ${ }^{2,4}$ School of Electrical Engineering, Faculty of Engineering, Universiti Teknologi Malaysia, Malaysia \\ ${ }^{2}$ Center for Artificial Intelligence and Robotics (CAIRO), Universiti Teknologi Malaysia, Malaysia \\ ${ }^{5}$ School of Biomedical Engineering and Health Sciences, Faculty of Engineering, \\ Universiti Teknologi Malaysia, Malaysia
}

\begin{tabular}{l} 
Article Info \\
\hline Article history: \\
Received Feb 9, 2019 \\
Revised May 10, 2019 \\
Accepted Mat 22, 2019 \\
\hline
\end{tabular}

\section{Keywords:}

Bending

Rotational

Soft actuator

Two-chambers

Underwater

\begin{abstract}
This paper presents a study on bending and rotational properties of twochambers soft actuator for underwater application. Previous study demonstrated the actuator characteristics required to optimize the bending performance and its potential to perform underwater because of the actuator material. However, there is less study of the actuator performance underwater as well as how the actuator tips rotating during actuator bending motion. In this paper, three tests have been proposed which are comparisons of bending angle simulation and experiment in air environment, bending angle performance in air and underwater environment as well as rotational angle of actuator tip in air environment. The bending angle of soft actuator is measured based on displacement in horizontal and vertical axis and for rotational angle, gyro sensor has been used. Based on the analysis, it is proven that the fabricated soft actuator performs almost similar trend to the simulation. It is also demonstrated that the actuator performs almost double bending motion underwater environment compared to in air environment at the same pressure, and the actuator is able to rotate $90^{\circ}$ in air environment with the supplied pressure $52 \mathrm{kPa}$.
\end{abstract}

Copyright $\odot 2019$ Institute of Advanced Engineering and Science. All rights reserved.

\section{Corresponding Author:}

Muhammad Rusydi Muhammad Razif,

Faculty of Engineering Technology,

Universiti Tun Hussein Onn Malaysia, Malaysia.

Email: rusydi@uthm.edu.my

\section{INTRODUCTION}

Recently, many underwater technologies have been developed to help humans maneuver underwater. Some researcher implemented biomimicry technique to generate thrust and produce high maneuvering such as "Thunniform swimmers" and "Humpback whale fins" [1]. They are using various kind of actuation technologies including electrical motor [2-4], shape memory alloy (SMA) [5], piezoelectric [6], Ionic Polymer-Metal Composite (IPMC) [7] and microelectromechanical system (MEMS) [8]. In producing a flexible movement such as Manta's wings [9], starfish robot [10] and Black Ghost Knife Fish's fin [11], soft actuator technology is selected to be used because of its high flexibility, simple structure, water resistance, high compliance and light weight [12]. Based on those advantages, soft actuator is predicted to have a great potential to be used in marine engineering technology as an alternative propulsion system for marine transportation in future.

The soft actuator technology is made from elastic material such as rubber and it is categorized into two types which are fiber reinforced and fiberless reinforced [13, 14]. It was first initiated by HF Schulte in 1960s by proposing McKibben muscle [15]. Schulte [15] focused his study on the effect of braided pattern 
around the McKibben muscle towards actuator movement when pressurized, either it performed contraction, extension, or stiffness change. The studied was further continued by many researchers to improve the mechanism and performance of soft actuator. Latest design of the soft McKibben actuator used thin structured [16-18] and the innovation in its fabrication technique improved time taken to complete an actuator fabrication in less than hour. This technique introduced a method to use ready-made silicone tube and knitting fiber, then sealed them with caps at both ends of the actuator [19]. In bending characteristic operation, some investigators had proposed multiple chambers for bending in high degree of freedom [20], while others suggested new design and new braiding techniques such as Bellow structure [21-23] and combining different pattern fiber weave [24]. All the proposed methods and approaches have its advantages and limitation depending on the application needed. For example, in Bellow structure, the actuator required small amount of supplied pressure compared to other design and it could be flapping in right and left direction by supplied positive pressure and negative pressure [25]. However, the load that it could withstand is low. The different pattern fiber weave in soft actuator developed by Faudzi et al. [26] as mentioned earlier improved the technique in bending motion without the need of two or more actuators as done by Suzumori $e t$ al. [27]. But the different pattern fiber weave actuator has limitation as it could bend to one direction in a single degree of freedom. Multiple chambers in the other hand has proven great number degree of freedom, but its molding and fabrication process become more complex.

Although many inventions in soft actuator design and application recently, there are more studies on two-chambers soft actuator has been unnoticed. Latest study in two-chambers soft actuator has been advancing on optimal bending characteristic design and application in robotic [12]. The two chambers soft actuator has great potential to be explored in flapping application because of its advantage to bend symmetrically in right and left direction [12], and its body made from elastic and waterproof material make it suitable for underwater usage. Thus this paper presents the continuation study on two chambers soft actuator by comparing its bending performance in air and water environment as well as actuator's rotational performance as supplied pressure increased. The two-chambers bending actuator is simulated initially in finite element software and its performance is then validated experimentally. This characteristic studies of two chambers soft actuator bending performance in air environment and underwater as well as its tips rotational performance are needed for future application in robotic that using flapping motion underwater such as bionic robotic fin or safe actuation propeller for a boat.

\section{METHODOLOGY}

The methodology of two chambers soft actuator bending and rotational properties started by designing and simulating two-chambers soft actuator in finite element analysis software. After the simulation study has been completed, the mold will be prepared and then the actuator will be fabricated. Once the actuator is ready, the testing for bending performance in air environment and water environment as well as tip rotation will be conducted by supplying pneumatic pressure inside the actuator's chamber. The supplied pressure will be increased by $5 \mathrm{kPa}$ up to $75 \mathrm{kPa}$ and the results of actuator bending and tip rotation will be computed. Then, the bending results in air environment and water environment will be compared.

The structural design of two-chambers soft actuator consists of a cylindrical rubber tube with two holes inside it as chambers, and reinforced with the fiber around its cylindrical body. Then, one end of the chambers is closed to ensure the supplied pressure enclosed in the chamber. The actuator bending occurs as the pressure in chamber increased because the fiber limiting actuator expansion in axial direction. As a result, actuator bends to the opposite direction in which the air pressure is supplied. In designing cross section area of the actuator, several criteria such as large chamber surface area, ratio of separating wall to actuator thickness is 2.5 , fiber location in the middle of actuator thickness, stiff fiber material and soft rubber material [12], need to be considered as these would be affecting the bending performance. The ratio of separating wall to actuator thickness is set to 2.5 because it has been proven to be the optimized design for two-chambers soft actuator bending performance as simulated and experimented by Suzumori et al. [9]. The cross sectional area of the actuator is illustrated as in Figure 1. We firstly set the actuator diameter and actuator length to 15.95 $\mathrm{mm}$ and $145 \mathrm{~mm}$ respectively. Then, we choose $3.625 \mathrm{~mm}$ and $1.45 \mathrm{~mm}$ values for separating wall thickness and actuator thickness respectively to ensure the ratio between them is 2.5 . These values are chosen to have an optimized size of chamber surface area and possible to be fabricated with the current available technology. Rubber and fiber materials used in two-chambers soft actuator are room temperature vulcanization (RTV) and nylon with soft and stiff characteristics respectively. The rubber is made by RTV-3481 from Xiameter ${ }^{\circledR}$ with $1.7338 \mathrm{MPa}$ Young Modulus and 0.49 Poisson's ratio whereas the fiber is nylon type with $3000 \mathrm{kPa}$ Young modulus and 0.3 Poisson's ratio. The characteristics of actuator's structure and its materials are simplified in Table 1 and Table 2. 


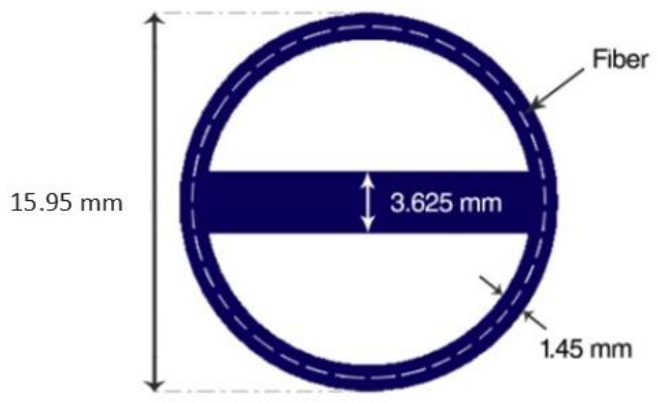

Figure 1. Cross sectional design of two-chambers soft actuator

Table 1. Actuator's structure

\begin{tabular}{cc}
\hline \multicolumn{2}{c}{ Table 1. Actuator's structure } \\
\hline Properties & Values \\
\hline Actuator length & $145 \mathrm{~mm}$ \\
Actuator diameter & $15.95 \mathrm{~mm}$ \\
Actuator thickness & $1.45 \mathrm{~mm}$ \\
Wall thickness & $3.625 \mathrm{~mm}$ \\
\hline
\end{tabular}

Table 2. Actuator's material

\begin{tabular}{cc}
\hline Properties & Values \\
\hline Young modulus of rubber & $1.7338 \mathrm{kPa}$ \\
Young modulus of fiber & $3000 \mathrm{kPa}$ \\
Poisson's ratio of rubber & 0.49 \\
Poisson's ratio of fiber & 0.3 \\
\hline
\end{tabular}

After the dimension and material for soft actuator are selected, the analysis is conducted in finite element simulation using MARC $^{\circledR}$ software to predict its bending angle performance. MARC ${ }^{\circledR}$ has been chosen as simulation tool because it provides optimized solution for nonlinear analysis of static, dynamic and multi-physics condition which is suitable for soft actuator model. In MARC ${ }^{\circledR}$ software, 6376 elements have been created to form an actuator with the top part of the actuator is set to fix. Then, boundary condition is set to one of the actuator chambers with pressure of $0 \mathrm{kPa}$ to $75 \mathrm{kPa}$. After that, any changes in horizontal and vertical displacement of actuator tip is computed for measurement of bending angle and any tip rotation in $\mathrm{z}$ axis is measured as in Figure 2. In Figure 2, $\alpha$ represent the bending angle of the actuator after pressurized and $B$ represent the angle of tip rotation of the actuator.
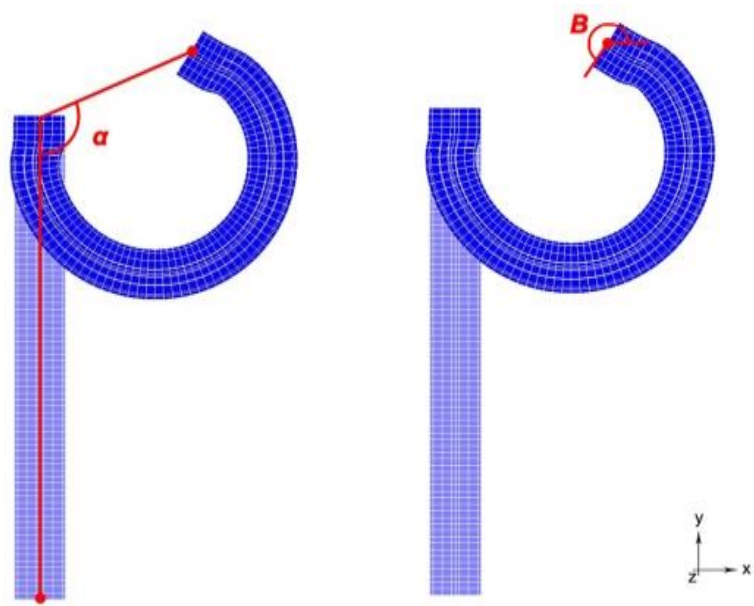

Figure 2. Bending angle measurement (left) and rotation angle measurement (right)

In actuator fabrication process, the mold need to be ready first. Three sets of mold were prepared named inner mold, outer mold and two rods with holder using CAD software and they were fabricated using Roland CNC machine. Inner thickness is fabricated first using inner mold and two rods with holder were put in the middle of the mold to make chambers. Then, an amount of liquid rubber is poured into the mold. After the rubber hardened, the fiber is coiled around the inner thickness and then it is put into outer mold for finishing process. Again, another rubber with mixing curing agent is poured into the outer mold to make the outer thickness. Figure 3 and Figure 4 illustrated the molds and the fabricated actuator.

Two-chambers soft actuator bending and rotational properties .... (Muhammad Rusydi Muhammad Razif) 

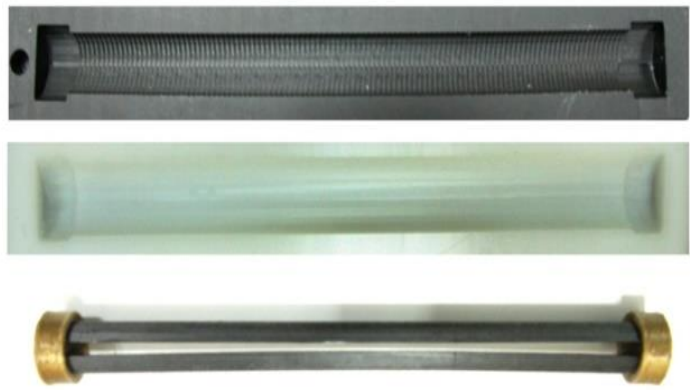

Figure 3. Actuator mold. From above - Inner mold, outer mold and rod with holder

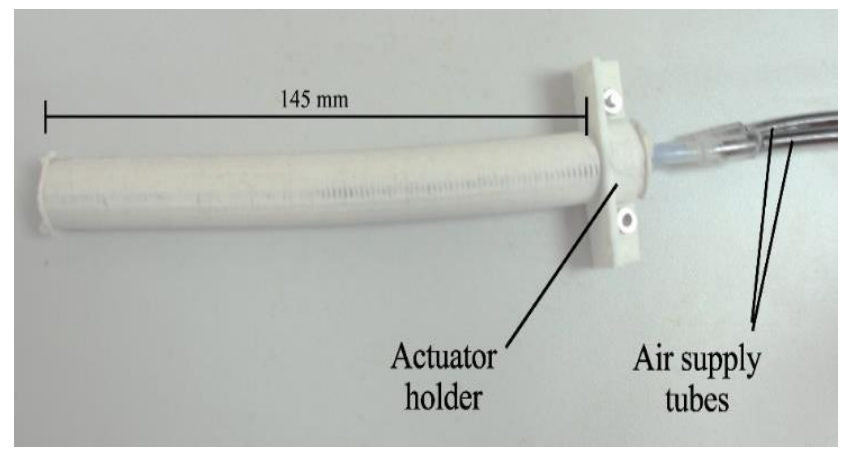

Figure 4. Fabricated soft actuator

In experimental analysis, three tests are conducted to investigate the performance of soft actuator. Initially, the simulation of bending angle actuator is validated with the fabricated actuator in air environment. Then, the same testing is repeated in water environment and the differences between them are compared. The experimental testing of both is important as it tell us how much pressure is needed for the actuator to bend in specific angle. Finally, the actuator tip rotational is measured to see the the curling behavior of the actuator. This measurement is needed for certain applications for example in gripping purpose, it requires the actuator tip to at least rotate to $180^{\circ}$ to touch the top of the actuator. Note that the rotation angle is not conducted in water environment as the gyro sensor is not suitable for non-water proofed condition.

For all experimental setup, one end of the actuator is fixed to an actuator holder and the pneumatic pressure is inserted into one of the actuator chamber through a small tube on its upper part. Then the pressure is inserted and increased by $5 \mathrm{kPa}$ from $0 \mathrm{kPa}$ to $75 \mathrm{kPa}$ to produce bending motion. Next, the changes in bending angle and tip rotation angle are measured. The actuator setup for all tests and its final motion after being pressurized by pneumatic supply are illustrated in Figure 5. Figure 5(a) shows the actuator being tested in air environment for bending motion whereas Figure 5(b) shows the actuator being tested underwater for bending motion. For bending angle measurement, Figure 2 is referred. From the figure, any changes of soft actuator tip are captured by using high resolution camera and the changes in horizontal and vertical displacement it is measured. After that, the bending equation are derived as in Equation (1) and Equation (2). In those equations, $\alpha$ represents bending angle of the actuator, measured on actuator tip displacement in horizontal and vertical axes [10]. Displacement of actuator tip in horizontal and vertical axes are represented by $\mathrm{x}$ and $\mathrm{y}$, whereas values in $\mathrm{z}$-axis is neglected because of very small reading observed. The $\mathrm{y}$ value is compared to $145 \mathrm{~mm}$ because of the height of the actuator. The same procedure is repeated for bending measurement in water environment and discussed in next section.

$$
\begin{aligned}
& \alpha=\tan ^{-1}\left[\frac{x}{145-y}\right], \text { if } y \text { is less than } 145 \mathrm{~mm} \\
& \alpha=90+\tan ^{-1}\left[\frac{y-145}{x}\right], \text { if } y \text { is greater than } 145 \mathrm{~mm}
\end{aligned}
$$


For rotation angle measurement, it is attained directly using MPU-6050 gyro sensor that displayed in Arduino ${ }^{\circledR}$ real time serial monitor. Gyro sensor is a useful device which able to sense any changes in 3-axis rotations, usually called yaw, pitch and roll. In our situation, we activated only the pitch rotation because the tip of the actuator is rotating in y-axis. As the pressure in actuator's chamber increase, the actuator tip starts to rotate, caused the gyro sensor activated measurement of rotation rate around a particular axis; $\mathrm{x}, \mathrm{y}$ and $\mathrm{z}$. For rotational calculation, Figure 2 has been referred where the axis orientation, B can be derived by integrating the rate of rotation over time as in Equation (3). Figure 6 shows the rotational measurement using gyro sensor and its final motion after being pressurized with pneumatic supply.

Angle of $y$ axis, $B=\int$ Rate of rotation

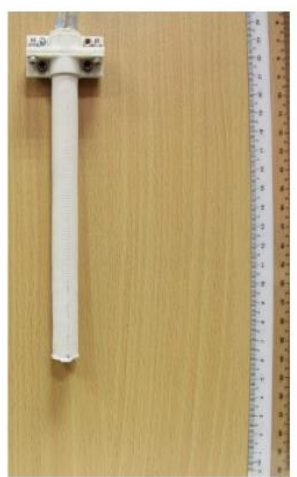

(a)
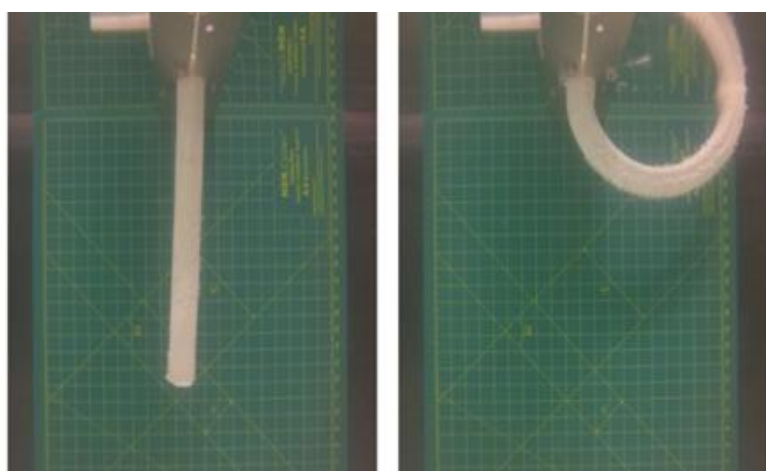

(b)

Figure 5. (a) Bending angle measurement in air environment before and after pressurized (b) Bending angle measurement in water environment before and after pressurized
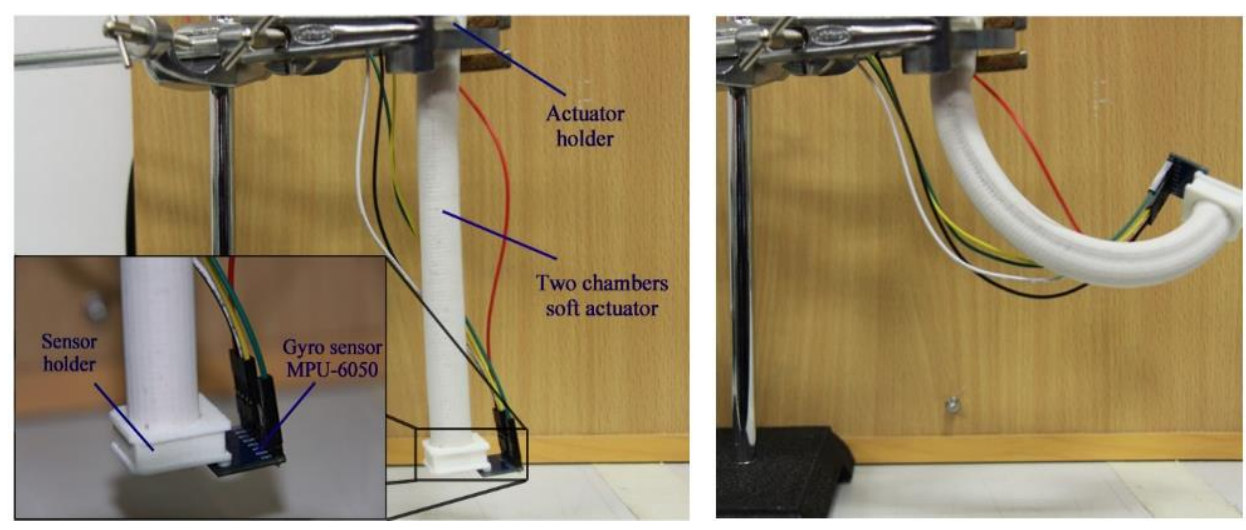

Figure 6. Actuator with gyro sensor before pressurized (left) and rotation angle measurement after pressurized (right)

\section{RESULTS AND DISCUSSION}

The aims of this study are to analyze the performance of two-chambers soft actuator in air environment and underwater as well as its rotational characteristic. By having a comprehensive data on twochambers soft actuator performance, the potential of actuator to be applied in modern technology would contribute benefits in future safe actuation motion underwater. In this study, the data collected are simulation of bending performance of the actuator as well as its experimental results. Both results are plotted in Figure 7(a) against pneumatic supplied pressure. The same actuator is then set underwater and the bending performance are plotted in Figure 7(b) against pneumatic supplied pressure. In Figure 7(c), the rotational tip of the actuator motion is recorded against pneumatic supplied pressure. The increment in pneumatic supplied pressure were set to $5 \mathrm{kPa}$ for all experimental testing until the maximum $75 \mathrm{kPa}$ pressure applied. 


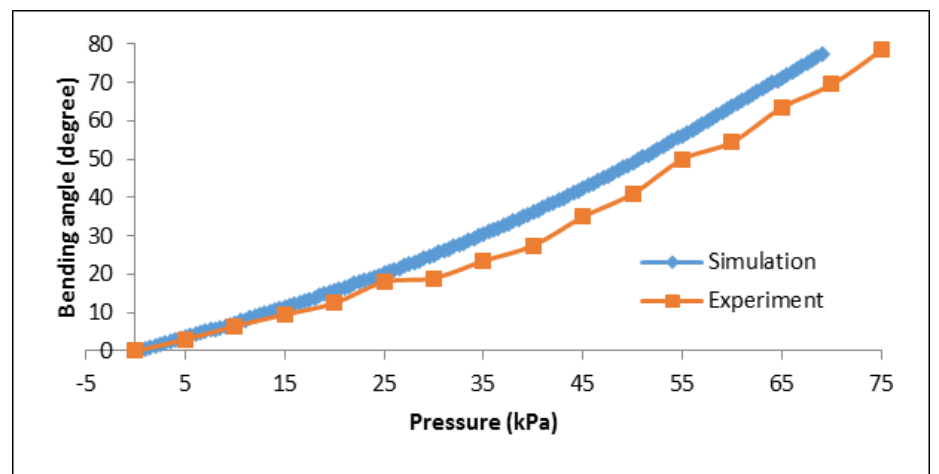

(a)

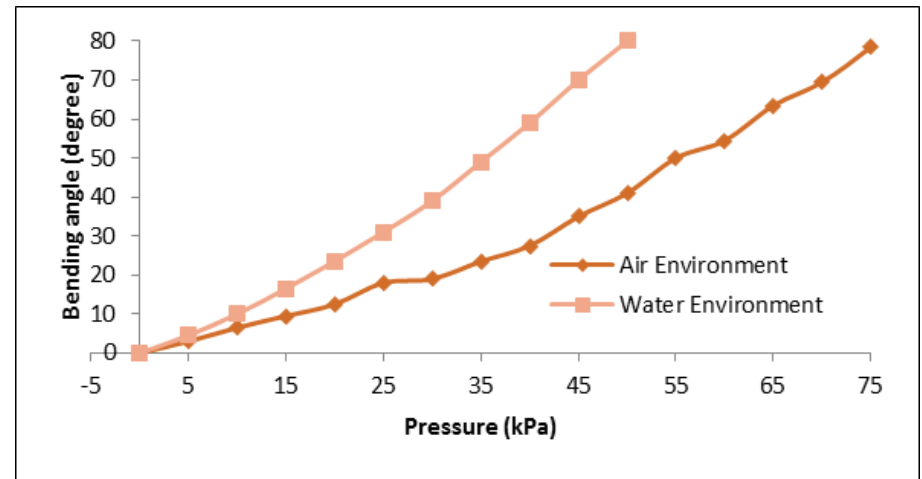

(b)

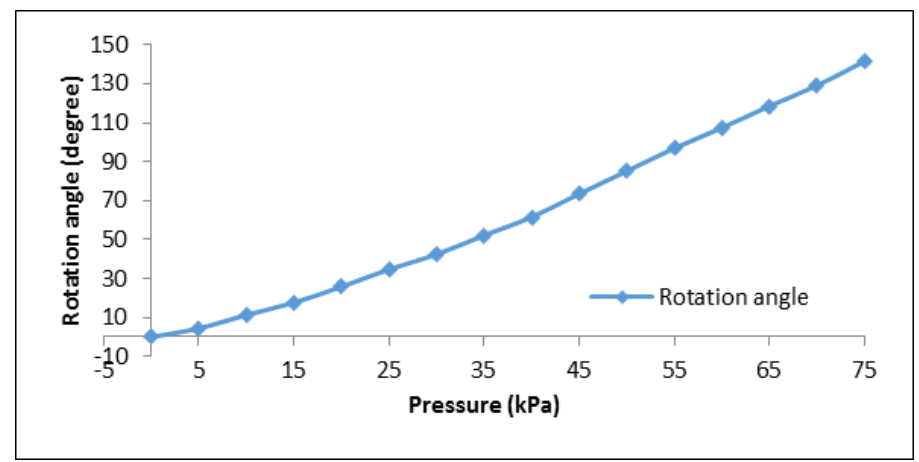

(c)

Figure 7. (a) Bending angle of the actuator in simulation and experiment in air environment (b) bending angle of the actuator in air and water environments (c) Rotation of the actuator tip in air environment

In Figure 7(a), both simulation and experiment results for the actuator bending angle in air environment increased as the supplied pressure increased. The trends are almost similar at low pressure supplied (below $25 \mathrm{kPa}$ ) and the difference bending reading occur at higher pressure supplied. The average bending angle difference between both graphs is from $5^{\circ}$ to $8^{\circ}$ for a condition of same supplied pressure in simulation and experiment. The difference represent error of $16 \%$ at supplied pressure $30 \mathrm{kPa}$ and it reduced to $7 \%$ as the supplied pressure reached maximum $75 \mathrm{kPa}$. The low error in nonlinear material could be considered acceptable, thus validate the simulation model.

In Figure 7(b), the same experimental results of bending performance in air environment as in Figure 7(a) is compared to the experimental underwater. From observation, it shows that the actuator performs more bending in water environment at the same supplied pressure with the value of bending underwater almost double. For example, at the supplied pressure $20 \mathrm{kPa}$, the actuator bending angles underwater and air environment computed are $23.5^{\circ}$ and $12.5^{\circ}$ respectively. The double value difference in bending angle performance for both conditions is still the same even though the supplied pressure has been increased. For example, at supplied pressure $50 \mathrm{kPa}$, the bending angle underwater computed showed almost 
double values compared to air environment with the values $80^{\circ}$ and $41^{\circ}$ respectively. The larger bending angle performance underwater occur because of pneumatic pressure inside the actuator chamber caused the buoyancy effect and make the actuator's weight lighter. It could be concluded that the performance of actuator's bending angle underwater almost double compared to the same actuator in air environment.

In Figure 7(c), the measurement of actuator tip rotation has been conducted. From observation, the rotation of soft actuator tip increase almost linear as the supplied air pressure increase. The actuator is able to rotate to $90^{\circ}$ at $52 \mathrm{kPa}$ supplied pressure and continue to rotate until maximum $150^{\circ}$ as supplied pneumatic pressure approaches maximum $75 \mathrm{kPa}$. It is more interesting to know how much the supplied pressure required to obtain $90^{\circ}$ rotation because this is the condition where the tip start to chance the orientation from vertical to horizontal. In robotics application, the introduction of camera at the actuator's tip would benefit in controlling the camera visual field area.

\section{CONCLUSION}

The continuation study on two-chambers soft actuator has been conducted for bending performance in air and water comparison as well as tip rotation. Based on simulation and experiment study, the actuator shows almost similar bending performance in simulation and experiment with $78.5^{\circ}$ bending angle at maximum $75 \mathrm{kPa}$ supplied pressure. At the same amount of supplied pressure, the bending of soft actuator indicates almost double in underwater environment compared to in air environment due to the buoyancy effect. In tip rotation test, the actuator required $52 \mathrm{kPa}$ to change the tip orientation from vertical to horizontal. Considering all the characteristics, two-chambers soft actuator has a great potential to be used in underwater application such as for marine propulsion system for example in search and rescue purpose of flood victim. It is also suggested to perform more testing such as force measurement and control system for two-chambers soft actuator before it would be implemented in real system.

\section{ACKNOWLEDGEMENTS}

The authors would like to give special thanks to Universiti Tun Hussein Onn Malaysia (UTHM) under UTHM-Tier 1 Grant No. H136 and Ministry of Higher Education (MOHE) Malaysia.

\section{REFERENCES}

[1] M. Razif, et al., "A Review on Development of Robotic Fish,” Journal of Transport System Engineering, vol. 1, pp. 12-22, 2014

[2] Y. Bar-cohen, et al., "Biologically Inspired Intelligent Robotics," Electroactive Polymer Actuators and Devices, vol. 5051, pp. 14-20, 2003.

[3] H. H. H. Hu, et al., "Design of 3D Swim Patterns for Autonomous Robotic Fish," 2006 IEEE/RSJ International Conference on Intelligent Robots and Systems, pp. 2406-2411, 2006.

[4] M. Ariyanto, et al., "Anthropomorphic transradial myoelectric hand using tendon-spring mechanism," TELKOMNIKA Telecommunication Computing Electronics and Control, vol. 17, pp. 537-548, 2019.

[5] Z. W. Z. Wang, et al., "A micro biomimetic manta ray robot fish actuated by SMA," in 2009 IEEE International Conference on Robotics and Biomimetics (ROBIO), pp. 1809-1813, 2009.

[6] Q. S. Nguyen, et al., "Performance evaluation of an improved fish robot actuated by piezoceramic actuators," Smart Materials and Structures, vol. 19, pp. 035030, Mar 2010.

[7] M. R. M. Razif, et al., "Non-Linear Finite Element Analysis of Biologically Inspired Robotic Fin Actuated by Soft Actuators," Applied Mechanics and Materials, vol. 528, pp. 272-277, 2014.

[8] R. E. Pawinanto, et al., "Design and Fabrication of Compact MEMS Electromagnetic Micro-Actuator with Planar Micro-Coil Based on PCB," TELKOMNIKA Telecommunication Computing Electronics and Control, vol. 14, 2016.

[9] K. Suzumori, et al., "A bending pneumatic rubber actuator realizing soft-bodied manta swimming robot," in Proceedings, IEEE International Conference on Robotics and Automation, pp. 4975-4980, 2007.

[10] R. F. Shepherd, et al., "Multigait soft robot," in Proceedings of the national academy of sciences, vol. 108, pp. 20400-20403, 2011

[11] D. Trivedi, et al., "Soft robotics: Biological inspiration, state of the art, and future research," Applied bionics and biomechanics, vol. 5, pp. 99-117, 2008

[12] M. R. M. Razif, et al., "Two chambers soft actuator realizing robotic gymnotiform swimmers fin," in IEEE International Conference on Robotics and Biomimetics, pp. 15-20, 2014.

[13] A. M. Faudzi, et al., "Development of Flexible Bronchoscope Device Using Soft Actuator," in Medical Imaging Technology, Springer, pp. 223-241, 2015.

[14] I. N. A. M. Nordin, et al., "3-D finite-element analysis of fiber-reinforced soft bending actuator for finger flexion," in IEEE/ASME International Conference on Advanced Intelligent Mechatronics, pp. 128-133, 2013. 
[15] H. F. Schulte Jr, "The characteristics of the McKibben artificial muscle (1961) The Application of external power in prosthetics and orthotics," National Academy of Sciences-National Research Council, Washington DC, Appendix H, pp. 94-115, 1961.

[16] A. A. M. Faudzi, et al., "Soft-Amphibious robot using thin and soft McKibben actuator," IEEE/ASME International Conference on on Advanced Intelligent Mechatronics, pp. 981-986, 2017.

[17] A. A. M. Faudzi, et al., "Modeling and force control of thin soft McKibben actuator," International Journal of Automation Technology, vol. 10, pp. 487-493, 2016.

[18] A. A. M. Faudzi, et al., "Long-Legged Hexapod Giacometti Robot Using Thin Soft McKibben Actuator," IEEE Robotic and Automation Letters, vol. 3, pp. 100-107, 2018.

[19] S. Kurumaya, et al., "Design of thin McKibben muscle and multifilament structure," Sensors and Actuators A: Physical, vol. 261, pp. 66-74, 2017.

[20] K. Suzumori, et al., "Development of flexible microactuator and its applications to robotic mechanisms," in IEEE International Conference on Robotics and Automation, pp. 1622-1627, 1991.

[21] T. Rehman, et al., "Design, characterization, and manufacturing of circular bellows pneumatic soft actuator," The International Journal of Advanced Manufacturing Technology, vol. 93, pp. 4295-4304, 2017.

[22] T. Rehman, et al., "Design and Analysis of Bending Motion in Single and Dual Chamber Bellows," Jurnal Teknologi, vol. 78, pp. 17-23, 2016.

[23] M. Sfakiotakis, et al., "An experimental undulating-fin device using the parallel bellows actuator," IEEE International Conference on Robotics and Automation, vol. 3, pp. 2356-2362, 2001.

[24] I. N. A. M. Nordin, et al., "Simulations of two patterns fiber weaves reinforced in rubber actuator," Jurnal Teknologi, vol. 69, pp. 133-138, 2014.

[25] S. Wakimoto, et al., "Miniature pneumatic curling rubber actuator generating bidirectional motion with one airsupply tube," Advanced Robotics, vol. 25, pp. 1311-1330, 2011.

[26] A. A. M. Faudzi, et al., "Development of bending soft actuator with different braided angles," IEEE/ASME International Conference on Advanced Intelligent Mechatronics, pp. 1093-1098, 2012.

[27] K. Suzumori, et al., "Long bending rubber mechanism combined contracting and extending tluidic actuators," IEEE International Conference on Intelligent Robots and Systems, pp. 4454-4459, 2013.

\section{BIOGRAPHIES OF AUTHORS}

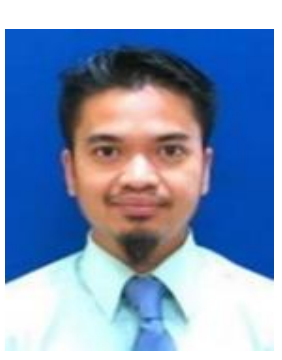

Dr. Muhammad Rusydi Muhammad Razif obtained his PhD degrees in in the field of Soft Robotics Engineering from Universiti Teknologi Malaysia, Malaysia. Currently he is working as a lecturer in Faculty of Engineering Technology of the Universiti Tun Hussein Onn Malaysia. His teaching and research interests include robotics, mechanisms, bioinspired, and mechatronics design. He has been the senior researcher of Cybernetics Research Group UTHM and the affiliate researcher of Sustainable Transport and Safety Studies UTHM. He is a member of Board of Engineer Malaysia (BEM).

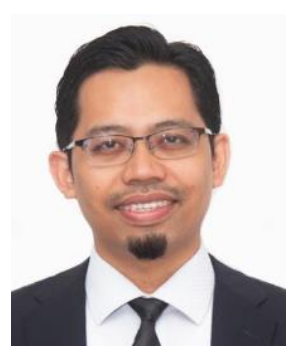

Assoc. Prof. Ir. Dr. Ahmad 'Athif Mohd Faudzi is the director of Centre for Artificial Intelligence and Robotics (CAIRO), Universiti Teknologi Malaysia, Malaysia. He received the B. Eng. in Computer Engineering, the M. Eng. in Mechatronics and Automatic Control from Universiti Teknologi Malaysia, Malaysia and the Dr. Eng. in System Integration from Okayama University, Japan in 2004, 2006, and 2010 respectively. He was a Visiting Research Fellow at Tokyo Institute of Technology from 2015 to 2017. He is mainly engaged in the research fields of pneumatic actuators, soft mechanism actuators, hydraulic actuators, automation and control in industrial robots, biomedical applications and bio-robotics. He is a Professional Engineer (PEng), Charted Engineer (CEng) and members of IEEE Robotics and Automation Society (RAS).

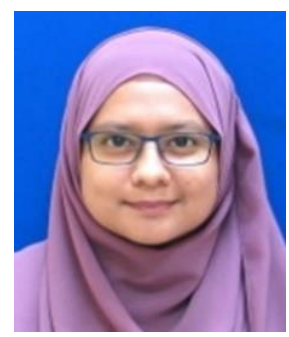

Dr. Ili Najaa Aimi Mohd Nordin obtained her B. Eng. Degree in Electrical-Medical Electronics Engineering and Ph.D degree in the field of Soft Robotics Engineering from Universiti Teknologi Malaysia, Malaysia. Currently, she is working as a lecturer in the Department of Electrical Engineering Technology, Faculty of Engineering Technology, Universiti Tun Hussein Onn Malaysia (UTHM). Her main research interests are in the areas of Electronics, Soft Robotics, Rehabilitation Robotics, Machine Learning and Wireless Monitoring. She is currently the head researcher of Cybernetics Research Group (CRG) in the UTHM, a member of Board of Engineer Malaysia (BEM), Institute of Engineers Malaysia (IEM) and Malaysia Board of Technologists (MBOT). 


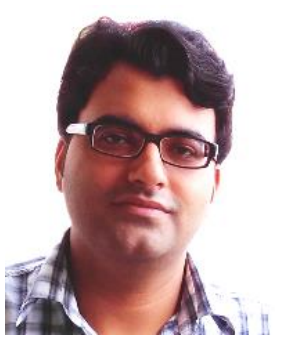

Mr. Tariq Rehman received his B.Eng. and M.Eng. degrees in Industrial Electronic Engineering from NED University of Engineering and Technology, Karachi, Pakistan in 2008 and 2012 respectively. $\mathrm{He}$ is currently research candidate towards the doctorate degree at Universiti Teknologi Malaysia, Skudai, Malaysia. His research interests are in the areas of soft mechanism, pneumatic actuators and their applications in bioinspired medical robots.

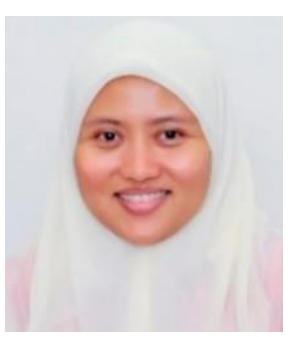

Dr. Dyah Ekashanti Octorina Dewi is a Senior Lecturer at School of Biomedical Engineering and Health Sciences, Faculty of Engineering, and Research Fellow at IJN-UTM Cardiovascular Engineering Center, Institute of Human Centered Engineering, Universiti Teknologi Malaysia, Johor Bahru, Malaysia. She obtained her PhD from BioMedical Engineering, Faculty of Medical Science, Universiti Medical Center Groningen - University of Groningen, The Netherlands. Her research interests include Image-guided navigation for surgery, Biomedical Imaging, Computer Vision, Phantoms, and Computational Human Models. 